\title{
Sympatric Distribution of Three Human Taenia Tapeworms Collected between 1935 and 2005 in Korea
}

\author{
Hyeong-Kyu Jeon', Kyu-Heon Kim², Jong-Yil Chai', Hyun-Jong Yang', Han-Jong Rim ${ }^{5}$ \\ and Keeseon S. Eom ${ }^{1, *}$ \\ 'Department of Parasitology and Medical Research Institute, Chungbuk National University College of Medicine, Chongju, Chungbuk 361-763, Korea; \\ ${ }^{2}$ Gyeongin Regional Food and Drug Administration, Incheon 402-835, Korea; 'Department of Parasitology and Tropical Medicine, Seoul National \\ University College of Medicine, and Institute of Endemic Diseases, Seoul National University Medical Research Center, Seoul 110-799, Korea; \\ ${ }^{4}$ Department of Parasitology, College of Medicine, Ewha Womans University, Seoul 158-710, Korea; ${ }^{5}$ Department of Parasitology, Korea University \\ College of Medicine, Seoul 136-705, Korea
}

\begin{abstract}
Taeniasis has been known as one of the prevalent parasitic infections in Korea. Until recently, Taenia saginata had long been considered a dominant, and widely distributed species but epidemiological profiles of human Taenia species in Korea still remain unclear. In order to better understand distribution patterns of human Taenia tapeworms in Korea, partial nucleotide sequences of mitochondrial cox1 and ITS2 (internal transcribed spacer 2) were determined, along with morphological examinations, on 68 Taenia specimens obtained from university museum collections deposited since 1935. Genomic DNA was extracted from formalin-preserved specimens. Phylogenetic relationships among the genotypes (cox1 haplotype) detected in this study were inferred using the neighbor-joining method as a tree building method. Morphological and genetic analyses identified 3 specimens as $T$. solium, 51 specimens as $T$. asiatica, and 14 specimens as $T$. saginata. Our results indicate that all 3 Taenia tapeworms are sympatrically distributed in Korea with $T$. asiatica dominating over $T$. saginata and T. solium.
\end{abstract}

Key words: Taenia solium, T. saginata, T. asiatica, sympatric distribution, molecular identification

\section{INTRODUCTION}

The cestodes of medical importance in Korea reportedly include Taenia and Diphyllobothrium tapeworms. Taeniasis and diphyllobothriasis are among the most prevalent types of human cestode infections in Korea [1]. Human taeniasis has become prevalent in Korea since the first report in 1924 [2]. A nationwide study was reported for the first time in 1969 by Seo et al. [3], and revealed a positive rate of $0.7 \%$ for taeniid eggs. Subsequent nationwide surveys conducted every 5 yr by MHSA (Ministry of Health and Social Affairs) and KAHP (Korea Association of Health Promotion) have revealed that the positivity rate for taeniid eggs decreased from $1.9 \%$ in 1969 to $0.02 \%$ in 1997 and human taeniasis was no more detected in the 2004 KAHP's survey. The infection ratio of $T$. solium versus $T$. saginata was roughly about $1: 5$ based on the collective data from researches reported between 1965 and 1988 [4]. The prevalence of taeniasis among Koreans was considered to be caused by

- Received 5 September 2008, accepted after revision 20 November 2008.

* Corresponding author (kseom@chungbuk.ac.kr) infection with T. saginata until Eom and Rim [5] revised the identification of the Korean Taenia tapeworm to establish a new species, T. asiatica. Differentiating human-infecting Taenia tapeworms is based mostly on the number of uterine branches in the proglottids or on the absence or presence of hooks on the scolex. However, the specificity of differentiation is low for direct observations of these tapeworms due to their morphological similarities, particularly in the eggs and proglottids of adult worms. Differential species identification between $T$. saginata and T. asiatica becomes even more difficult when stool sample examination is required because egg morphology is almost indistinguishable under light microcopy.

Epidemiologically, T. asiatica has been found in Taiwan, Korea, China, Indonesia, the Philippines, and Vietnam [4,6$11]$, and the overlapping distributions of the 2 tapeworms in these countries cause frequent confusion. The epidemiological status of the infections with T. asiatica, T. saginata, and T. solium were questionable in Korea, where this has been studied based on raw-food eating habits [4]. Consequently, it was necessary to clarify the distributions of these tapeworms in Korea.

Molecular approaches to differential diagnosis of human 
Taenia tapeworms have been developed in recent years, including the use of sequence-specific DNA probes, PCR-RFLP (restriction fragment length polymorphisms) [12,13], and multiplex PCR $[15,16]$. The present study used differences in the morphology, sequence variations in the mitochondrial cytochrome c oxidase I gene, and rDNA internal transcribed spacer II as markers for identifying 3 human Taenia tapeworms in Korea.

\section{MATERIALS AND METHODS}

\section{Specimens}

A total of 68 Taenia tapeworms were analyzed in this study (Table 1). These specimens were collected between 1935 and 2005 in the Republic of Korea. Some Taenia tapeworm proglottids were passed naturally in stools, or strobilae were discharged after treatment with niclosamide or praziquantel and purgation. The morphological features of the strobilae and proglottids were compatible with those of Taenia tapeworms. Mature proglottids were examined by light microscopy with carmine staining on the press-and-fixed specimen in an acetic-acid-formalin-alcohol solution. Twenty-nine specimens were preserved in $10 \%$ formalin, and 22 were kept in $70 \%$ ethanol, and 17 were kept in $-20^{\circ} \mathrm{C}$ or $-70^{\circ} \mathrm{C}$.

\section{DNA extraction}

Total genomic DNA was extracted from the tissues of terminal proglottids of Taenia tapeworms using the DNeasy Tissue Kit (Qiagen, Valencia, California, USA) according to the manufacturer's instructions and used as the template DNA for PCR amplification of the target gene fragments. Genomic DNA of specimens preserved in formalin was extracted using modified Azuma et al., [16] and Li et al., [17] protocols. The tissues (0.01 g) were crushed in liquid nitrogen and then soaked in TE buffer for 3-5 hr and then digested for $30 \mathrm{~min}$ in the DNA extraction buffer $(100 \mathrm{mM} \mathrm{NaCl}, 50 \mathrm{mM}$ EDTA in $\mathrm{pH} 8.0,50 \mathrm{mM}$ Tris in $\mathrm{pH}$ $8.0,10 \%$ SDS in $\mathrm{pH} 7.2$, and $20 \mathrm{mg} / \mathrm{ml}$ proteinase $\mathrm{K}$ ) at $56^{\circ} \mathrm{C}$. Samples in a hexadecyltrimethylammoniumbromide (CTAB)/ $\mathrm{NaCl}$ solution were incubated for $3 \mathrm{hr}$ at $65^{\circ} \mathrm{C}$. The cellular debris was removed and the genomic DNA was extracted using an extraction protocol with phenol-chloroform-isoamyl-alcohol (25: 24: 1, v/v/v). DNA was precipitated in $3 \mathrm{M}$ sodium acetate ( $\mathrm{pH} 5.2$ ) and a 2 times volume of $95 \%$ ethanol. The pellet was dissolved in $50 \mu \mathrm{l}$ of TE buffer (10 mM Tris-HCl and $\mathrm{l} \mathrm{mM}$ EDTA in $\mathrm{pH}$ 8.0). The genomic DNA was treated with RNAse $\mathrm{A}$ at $37^{\circ} \mathrm{C}$ for $30 \mathrm{~min}$ and kept at $-20^{\circ} \mathrm{C}$ until use. The extraction efficiency was examined using agarose-gel electrophoresis. The optical densities at 260 and $280 \mathrm{~nm}\left(\mathrm{OD}_{260}\right.$ and $\mathrm{OD}_{280}$, respectively) were measured by spectrophotometry.

\section{PCR}

The 5.8S-ITS2-28S regions of nuclear ribosome and the mitochondrial cox1 gene were targeted for PCR amplification. PCR reactions were performed in a reaction mixture of $50 \mu \mathrm{l}$ with $0.01 \mu \mathrm{g} / \mu \mathrm{l}$ of genomic DNA, $10 \times$ PCR buffer $\left(20 \mathrm{mM} \mathrm{Mg}^{+}\right)$, $10 \mathrm{mM}$ dNTP mixture, 10 pmoles of each primer, and $2.5 \mathrm{U} / \mu \mathrm{l}$ Taq DNA polymerase (High Fidelity PCR system, Roche, Mannheim, Germany). PCRs were performed in a GeneAmp PCR System 9700 (Applied Biosystems, Langen, Germany) and involved 1 cycle of initial denaturation at $94^{\circ} \mathrm{C}$ for $3 \mathrm{~min}$, followed by 35 cycles of denaturation $\left(94^{\circ} \mathrm{C}\right.$ for $\left.1 \mathrm{~min}\right)$, annealing $\left(46^{\circ} \mathrm{C}\right.$ for $1 \mathrm{~min}$ for $\operatorname{cox} 1 ; 66^{\circ} \mathrm{C}$ for $30 \mathrm{sec}$ for ITS2), and extension $\left(72^{\circ} \mathrm{C}\right.$ for $\left.1 \mathrm{~min}\right)$, with a final extension at $72^{\circ} \mathrm{C}$ for $10 \mathrm{~min}$. The PCR primers used were 687 (5'-GTTAGTTTCTTTTCCTC-3') and CS250 (5'-ACCCTGGACGGTGGATCACTCGG-3') for ITS2 which yielded a 534-bp product including 5.8S rDNA and 28S rDNA, corresponding to positions 2723-745 and 3347-3362 of the Drosophila melanogaster rDNA sequence (GenBank M21017); and T1F (5'-ATATTTACTTTAGATCATAAGCGG-3') and T1R (5'-ACGAGAAAATATATTAGT CATAAA-3') for cox1 which yielded a 348-bp product. The PCR amplification products were directly sequenced using DNA sequencer (3730XL, model Applied Biosystems) and the Big-Dye Terminator Cycle Sequencing Reaction Kit (version 3.2, Applied Biosystems).

\section{DNA sequencing and analyses}

The sequences of cox 1 and the ITS2 regions from Taenia tapeworm specimens were aligned using the CLUSTAL X multiple alignment program [18] and the Bioedit programs (version 5.0.6, BIOSOFT, Ferguson, Missouri, USA). The molecular identification of Taenia tapeworm specimens was based on the similarity of nucleotide sequences and phylogenetic relationships with those of T. asiatica (GenBank NC 004826), T. saginata (GenBank AB066495) and T. solium (GenBank NC 004022). Phylogenetic relationships among the Taenia genotypes were inferred using different tree-constructing algorithms, i.e., neighbor-joining (NJ), maximum parsimony (MP), and minimum evolution (ME), using the Mega 3.1 program [19]. NJ analysis was performed based on corrected distance matrix of the Kimura's 2 parameter substitution model. Bootstrap analysis was performed with 3,000 replications. The mitochondrial cox 1 
Table 1. Samples analyzed in this study

\begin{tabular}{|c|c|c|c|c|c|}
\hline Code & Species & Sex/age & Year & Locality & Fixation condition \\
\hline G1490 & T. asiatica & - & 1935 & Seoul & $10 \%$ Formalin \\
\hline G1485 & T. asiatica & $M / 10$ & 1971 & Chungju (Chungbuk) & $"$ \\
\hline G1496 & T. saginata & - & 1977 & - & " \\
\hline G1497 & T. saginata & $M / 36$ & 1978 & - & $"$ \\
\hline G1498 & T. solium & $\mathrm{F} / 50$ & 1979 & Uijeongbu (Gyeonggi) & $"$ \\
\hline G1494 & T. asiatica & $\mathrm{F} / 52$ & 1982 & Siheung (Gyeonggi) & " \\
\hline G1495 & T. saginata & $M / 36$ & 1982 & Siheung (Gyeonggi) & $"$ \\
\hline G1479 & T. asiatica & $M / 48$ & 1982 & Yongin (Gyeonggi) & " \\
\hline G1478 & T. saginata & $\mathrm{M} / 56$ & 1983 & Nonsan (Chungnam) & " \\
\hline G1481 & T. asiatica & $M / 51$ & 1983 & - & " \\
\hline G1489 & T. asiatica & $\mathrm{F} / 51$ & 1983 & Yeoncheon (Gyeonggi) & " \\
\hline G1482 & T. asiatica & $M / 55$ & 1983 & - & " \\
\hline G1477 & T. asiatica & $\mathrm{M} / 46$ & 1984 & - & " \\
\hline G1504 & T. saginata & $\mathrm{M} / 45$ & 1984 & Pyeongchang (Gangwon) & " \\
\hline G1507 & T. saginata & $\mathrm{M} / 44$ & 1984 & Pyeongchang (Gangwon) & " \\
\hline G1503 & T. saginata & $M / 64$ & 1985 & Haenam (Jeonnam) & " \\
\hline G1487 & T. asiatica & - & 1986 & - & " \\
\hline G1335 & T. asiatica & $M / 29$ & 1986 & Seoul & " \\
\hline G1506 & T. saginata & - & 1988 & - & " \\
\hline G1135 & T. asiatica & - & 1988 & Jeju & " \\
\hline G1336 & T. asiatica & - & 1989 & Cheongju (Chungbuk) & " \\
\hline K22 & T. asiatica & M & 1992 & Gimcheon (Gyeongbuk) & Frozen \\
\hline K23 & T. asiatica & $M / 64$ & 1992 & Gimcheon (Gyeongbuk) & " \\
\hline G1483 & T. asiatica & $\mathrm{F} / 51$ & 1992 & Gyeonggi & $10 \%$ Formalin \\
\hline G1101 & T. asiatica & - & 1993 & Chuncheon (Gangwon) & Frozen \\
\hline G1102 & T. asiatica & M & 1996 & Wanju (Jeonbuk) & " \\
\hline G1103 & T. asiatica & $\mathrm{F}$ & 1997 & Hwasun (Jeonnam) & $70 \%$ Ethanol \\
\hline G1104 & T. asiatica & M & 1997 & Hwasun (Jeonnam) & $"$ \\
\hline G1105 & T. asiatica & $\mathrm{F}$ & 1997 & Hwasun (Jeonnam) & " \\
\hline G1106 & T. asiatica & $\mathrm{F}$ & 1997 & Hwasun (Jeonnam) & $"$ \\
\hline G1107 & T. asiatica & $\mathrm{F}$ & 1997 & Hwasun (Jeonnam) & Frozen \\
\hline G1116 & T. asiatica & M & 1997 & Daegu & 70\% Ethanol \\
\hline G1117 & T. asiatica & M & 1997 & Youngju (Gyeongbuk) & " \\
\hline G1118 & T. asiatica & $\mathrm{M} / 57$ & 1997 & Wando (Jeonnam) & " \\
\hline G1119 & T. asiatica & $\mathrm{F} / 58$ & 1997 & Chuncheon (Gangwon) & 70\% Ethanol \\
\hline G1491 & T. asiatica & $\mathrm{F} / 57$ & 1997 & Wando (Jeonnam) & $70 \%$ Ethanol \\
\hline G1138 & T. asiatica & $\mathrm{M} / 59$ & 1998 & Ansan (Gyeonggi) & " \\
\hline G1140 & T. saginata & $\mathrm{F} / 46$ & 1998 & Busan & $"$ \\
\hline G1484 & T. saginata & $\mathrm{M} / 57$ & 2000 & - & $"$ \\
\hline G1190 & T. asiatica & $\mathrm{M} / 49$ & 2000 & Cheonan (Chungnam) & Frozen \\
\hline G1192 & T. asiatica & - & 2000 & Jeju & $70 \%$ Ethanol \\
\hline G1279 & T. asiatica & $M / 43$ & 2002 & Seogwipo (Jeju) & " \\
\hline G1280 & T. asiatica & $F / 32$ & 2002 & Jeju & " \\
\hline G1292 & T. asiatica & $\mathrm{M} / 81$ & 2002 & Seogwipo (Jeju) & " \\
\hline G1299 & T. asiatica & $\mathrm{F} / 48$ & 2002 & Jeju & " \\
\hline G1499 & T. solium & $\mathrm{F} / 25$ & - & - & $10 \%$ Formalin \\
\hline G1500 & T. solium & $\mathrm{M} / 19$ & - & - & " \\
\hline G1501 & T. saginata & - & - & Yongin (Gyeonggi) & $"$ \\
\hline K3 & T. asiatica & $\mathrm{F}$ & - & - & Frozen \\
\hline K21 & T. asiatica & $M$ & - & Jeungpyeong (Chungbuk) & " \\
\hline K14 & T. asiatica & - & - & - & " \\
\hline K16 & T. asiatica & - & - & Seoul & " \\
\hline K17 & T. asiatica & - & - & Seoul & " \\
\hline K18 & T. asiatica & - & - & Seoul & " \\
\hline K24 & T. asiatica & - & - & - & " \\
\hline K19 & T. asiatica & - & - & Seoul & " \\
\hline
\end{tabular}


Table 1. (Continued from the previous page) Samples analyzed in this study

\begin{tabular}{llcccc}
\hline Code & Species & Sex/age & Year & Locality & Fixation condition \\
\hline K36 & T. asiatica & - & - & Cheongju (Chungbuk) & " \\
G1392 & T. asiatica & - & - & - & 10\% Formalin \\
K41 & T. asiatica & - & - & Cheongju (Chungbuk) & Frozen \\
K39 & T. asiatica & - & - & Cheongju (Chungbuk) & $10 \%$ Formalin \\
G1486 & T. asiatica & M/71 & - & - & $"$, \\
G1488 & T. asiatica & - & - & Cheongju (Chungbuk) & Jeju \\
G1281 & T. saginata & - & - & Jeju & $70 \%$ Ethanol \\
G1399 & T. asiatica & - & 2003 & - & $"$, \\
G1400 & T. asiatica & - & 2003 & Chuncheon & $"$, \\
G1403 & T. saginata & M/37 & 2003 & Jeju & $"$, \\
G1555 & T. asiatica & - & 2004 & 2005 &
\end{tabular}

- , unknown.

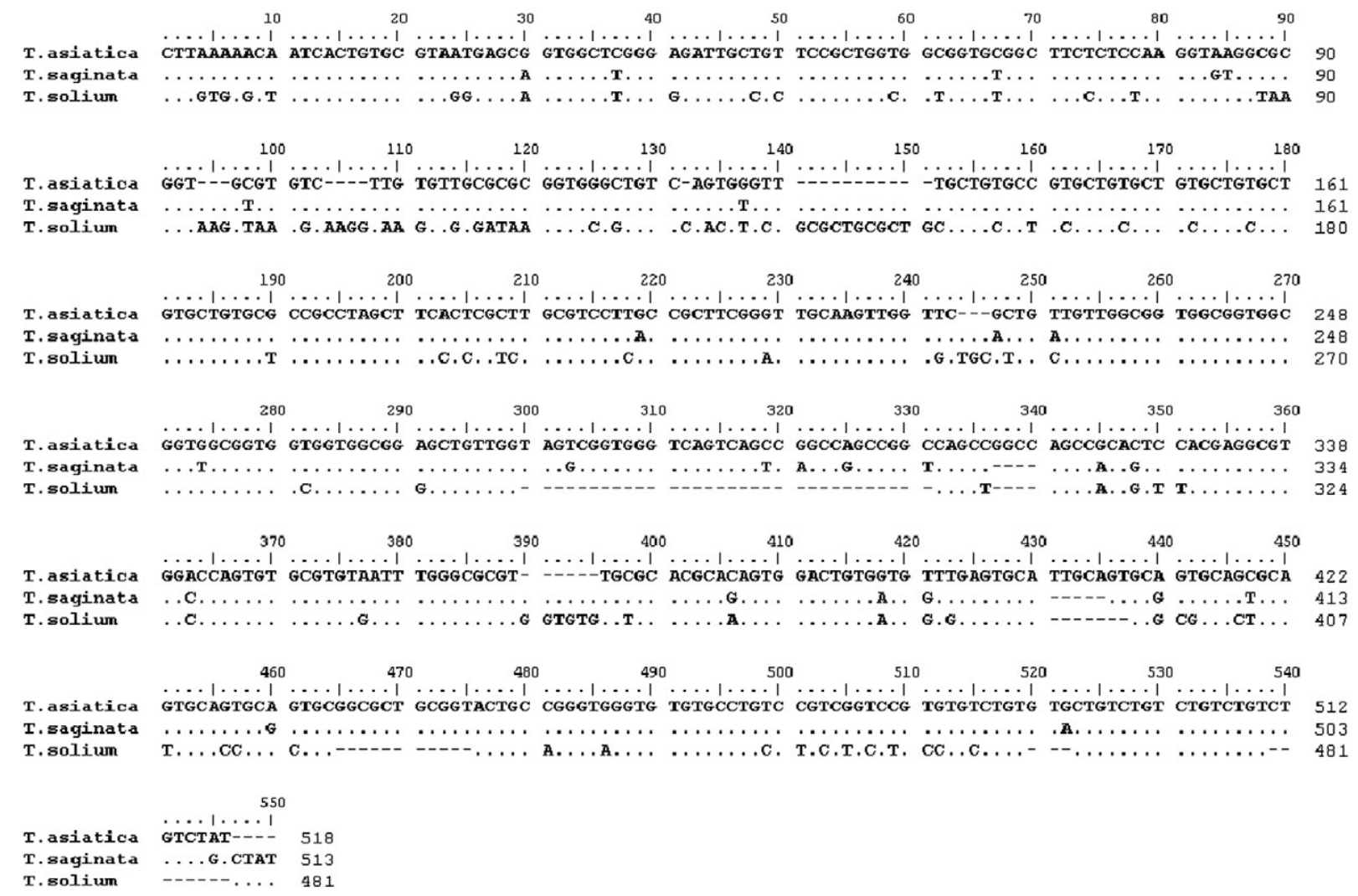

Fig. 1. Sequence alignment of ITS2 regions of human Taenia tapeworms. Dot (.) indicates identical nucleotide sequence to T. asiatica. Gap (-) was introduced for maximum alignments.

gene sequence of Echinococcus multilocularis (NC 000928) was used as an outgroup for phylogenetic analysis of cox1 dataset.

\section{RESULTS}

\section{Sequence divergence of cox1 gene and ITS2}

Taenia specimens were molecularly identified by direct sequ- encing of ITS2 and the partial mitochondrial cox1 region. ITS2 sequences of human Taenia tapeworms were ranged in length from 481 to $512 \mathrm{bp}$. The various lengths were represented by 503-bp and 512-bp sequences in T. saginata and T. asiatica, respectively, and 481-bp sequences in T. solium. The difference in the number of inferred gap among species ranged between 3 and $36 \mathrm{bp}$ in the human Taenia tapeworms (Fig. 1). The nucle- 
Table 2. Polymorphic sites of cox1 sequences of human Taenia tapeworms

\begin{tabular}{|c|c|c|c|c|c|c|c|c|c|c|c|c|c|c|c|c|c|c|c|c|c|c|c|c|c|c|c|c|}
\hline 115 & 138 & 153 & 174 & 183 & 189 & 190 & 195 & 219 & 225 & 231 & 234 & 237 & 243 & 247 & 252 & 261 & 265 & 267 & 268 & 270 & 273 & 280 & 285 & 288 & 291 & 300 & 3153 & 321324 \\
\hline Ts A & $\mathrm{G}$ & G & $\mathrm{T}$ & G & $\mathrm{T}$ & $\mathrm{T}$ & A & A & $\mathrm{T}$ & A & A & $\mathrm{T}$ & C & C & T & $\mathrm{T}$ & G & $\mathrm{T}$ & $\mathrm{T}$ & $\mathrm{T}$ & G & $\mathrm{T}$ & $\mathrm{T}$ & $\mathrm{T}$ & C & A & A & $A$ \\
\hline $\mathrm{Ta}$ & . & $\mathrm{T}$ & . & $\mathrm{T}$ & C & C & . & G & C & G & . & & $\mathrm{T}$ & $\mathrm{T}$ & & . & & & . & . & & & A & C & $\mathrm{T}$ & & $G$ & G \\
\hline Tsol T & A & & A & $\mathrm{T}$ & . & C & $\mathrm{T}$ & . & & . & $\mathrm{T}$ & A & $\mathrm{T}$ & $\mathrm{T}$ & C & A & A & A & A & A & A & G & & . & A & G & & $G \quad A$ \\
\hline 325 & 330 & 333 & 336 & 338 & 348 & 348 & 355 & 363 & 366 & 381 & 390 & 393 & 399 & 402 & 405 & 408 & 8411 & 421 & 422 & 423 & 425 & 426 & 429 & 432 & 438 & 4412 & 447 & 450 \\
\hline Ts A & $\mathrm{T}$ & A & G & C & G & G & T & G & T & G & T & $G$ & G & G & A & A & A & T & A & $\mathrm{T}$ & A & C & T & G & C & G & $\mathrm{T}$ & G \\
\hline $\mathrm{Ta}$ & . & G & A & $\mathrm{T}$ & A & . & . & . & . & A & . & & & . & $\mathrm{G}$ & . & & . & & . & . & T & & . & T & & C & \\
\hline Tsol G & $G$ & . & A & $T$ & $A$ & A & $G$ & A & C & $G$ & C & A & A & A & $\mathrm{T}$ & G & G & A & $\mathrm{G}$ & $A$ & $\mathrm{G}$ & $\mathrm{T}$ & $\mathrm{G}$ & A & $\mathrm{T}$ & $A$ & $\mathrm{~T}$ & $\mathrm{~T}$ \\
\hline
\end{tabular}

Numbers indicate the positions from $5^{\prime}$ end of the cox 1 gene, and dots indicate sequence matches with $T$. saginata. Ts, T. saginata; Ta, T. asiatica; Tsol, T. solium.

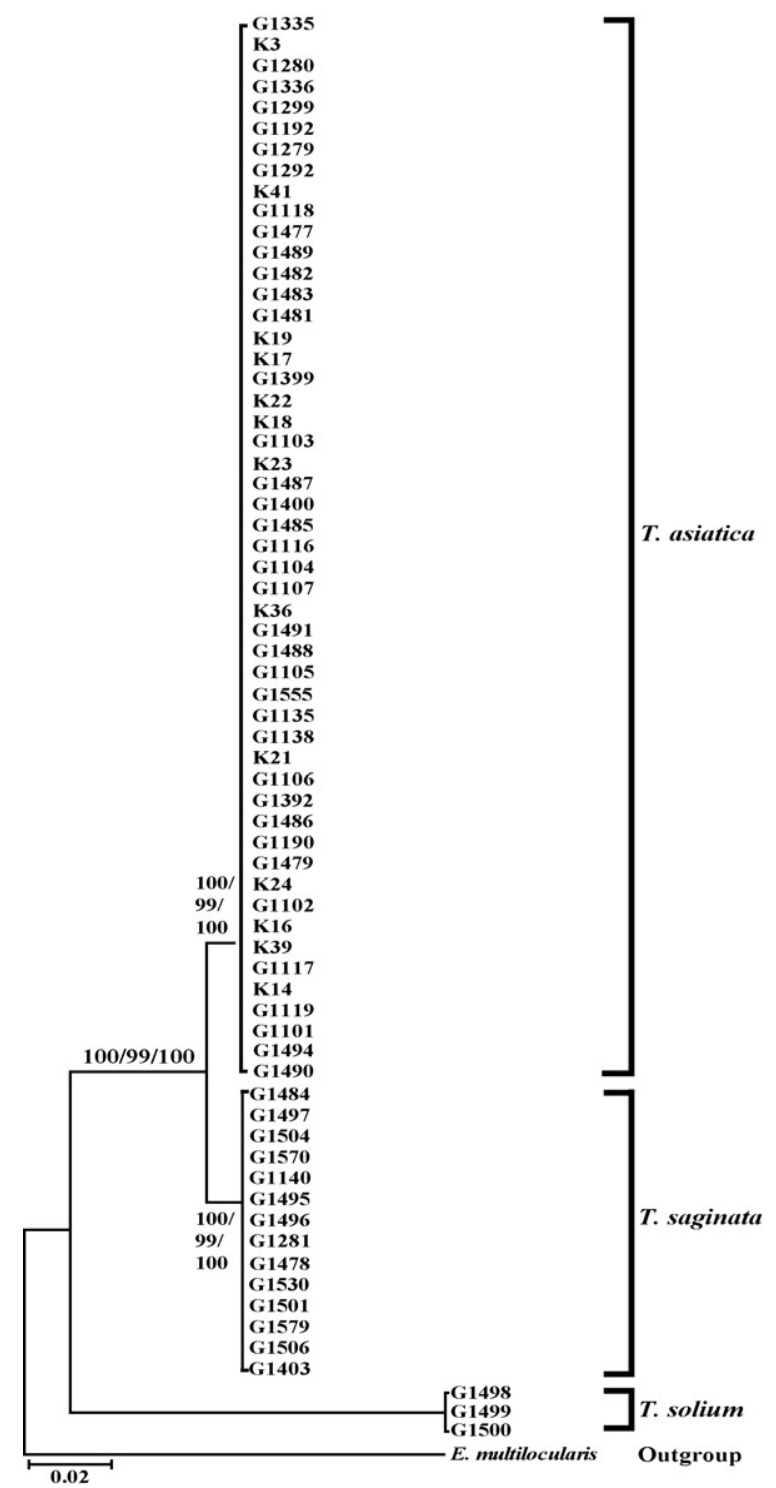

Fig. 2. Phyloge- netic trees of human Taenia tapeworms based on partial cox1 sequences in-ferred from neighbor-joining (NJ), maximum parsimony (MP), and minimum evolution (ME) analyses. Numbers on branches indicate the bootstrap supporting values.

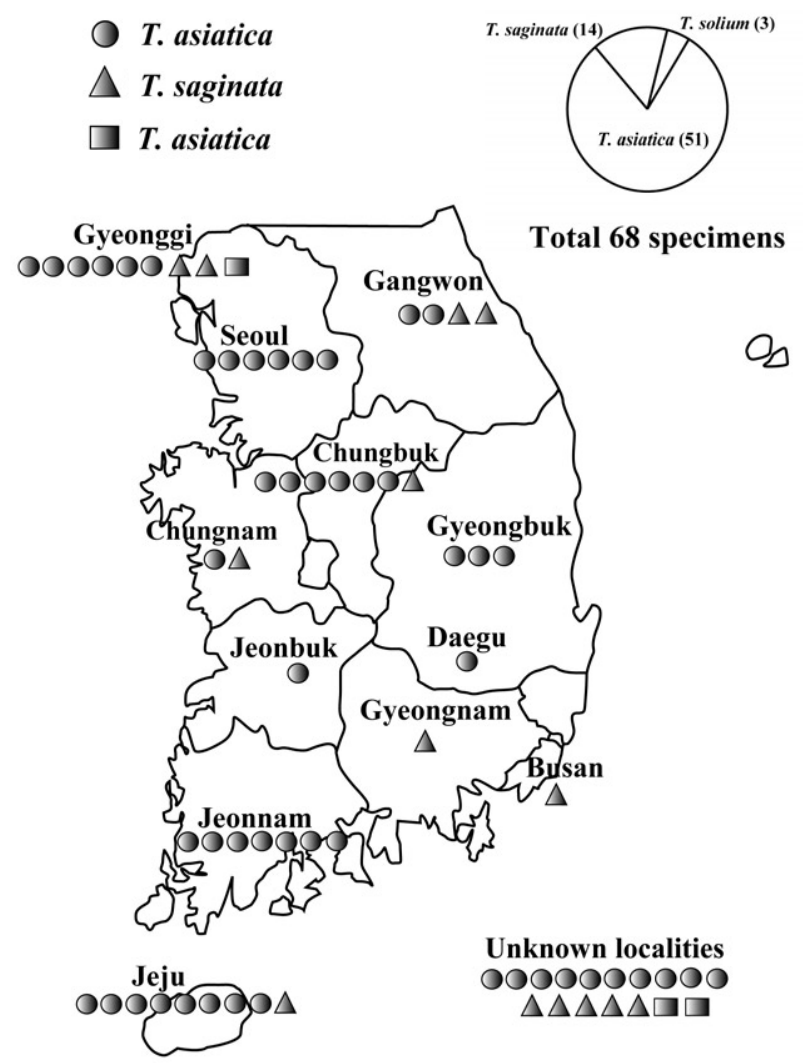

Fig. 3. Species composition and spatial distribution of human infecting Taenia tapeworms in Korea.

otide differences in these 3 species varied in size from 12 to 31 bp in the ITS2 region. The sequence divergenes of ITS2 between 3 Taenia species ranged from 7.3\% (T. saginata and T. asiatica) and $33.7 \%$ (T. asiatica and T. solium), respectively. The cox1 sequences (348 bp) showed 59 polymorphic sites, with 28 sites of nonsynonymous substitutions in human Taenia tapeworms (Table 2). The sequences of T. asiatica and T. saginata differed by $7 \%$, while those of T. saginata and T. solium differed by $15 \%$. Phylogenetic analysis of the mtDNA cox1 sequences for a total 
of 68 isolates (of which 51 were obtained from 9 identified provinces in Korea) identified T. solium as basal to the T. saginata-T. asiatica clade. Trees topology using various analytic methods (NJ, MP, and ME) generated was identical with very high confidence values (bootstrap values of 100\%, 99\%, and $100 \%$ in NJ, MP, and ME, respectively) for 3 major branches representing each of 3 species (Fig. 2).

\section{Species composition and spatial distribution}

Morphological and genetic analyses identified 3 specimens (from Gyeonggi and unknown localities) as Taenia solium, 51 specimens (from Chungbuk, Gangwon, Gyeonggi, Gyeongbuk, Jeonnam, Jeonbuk, Chungnam, Jeju, Seoul, Daegu, and unknown localities) as T. asiatica and 14 specimens (from Chungbuk, Gangwon, Gyeonggi, Chungnam, Busan, and unknown localities) as T. saginata. Most provinces exhibited 1 or 2 kinds of tapeworms except for Gyeonggi province that showed all 3 species of tapeworms. Ratios of T. solium: T. asiatica: T. saginata calculated from both morphological and molecular data was 3 : 51: 14 (or approximately 1: 17: 5). T. solium, T. saginata, and T. asiatica tapeworm infections were only exhibited in Gyeonggi province. T. saginata and T. asiatica tapeworm infections were presented in Gangwon, Chungbuk, Chungnam and Jeju provinces (Fig. 3). This result indicates that T. asiatica was the dominant human-infecting Taenia tapeworm in Korea.

\section{DISCUSSION}

Two types of taeniases (T. saginata and T. solium) were only recognized in Korea until 1992, with T. asiatica being newly described in 1993 as the third type of causative agent. T. saginata is morphologically distinct from $T$. asiatica by unarmed restellum, large number of uterine buds, and a posterior protuberance on the proglottids. Nevertheless, differential diagnosis of these species is often a task of specialists with much experience, especially when this is performed in field research conditions, which is hampered by the shortage of parasite materials obtained for examination or variable fixation/preservation conditions of the adult worms collected. These 2 species also exhibit different life cycles: with T. asiatica uses suids as intermediate hosts, whereas T. saginata utilizes bovids as intermediate hosts in order to complete their life cycles. This criterion, however, is not applicable in the laboratory condition. Even though the epidemiological understanding of T. asiatica infection remained questionable, T. asiatica rather than T. saginata, had been con- sidered to be the predominant species in Koera [4]. It was therefore necessary to quantify the prevalence of this tapeworm as well as those of $T$. saginata and T. solium. There was no Taenia egg positive case in the last nationwide survey of the presence of helminth eggs among Koreans, implemented in 2004, suggesting that the occurrence of Taneia species is rapidly decreasing. The difficulties of finding out Taenia-tapeworm-infected individuals prompted us to plan to analyze collections available over all time, dating back up to 1935 from laboratories and institutes, and including any sources of tapeworms in Korea. Recent ad- vancements in DNA analysis techniques made it possible to differentiate species precisely, but the results were not consistent with epidemiological finding.

Twenty-nine of the 68 examined specimens were preserved in $10 \%$ formalin, which can cause cross-linking between DNA and protein, and also degrade DNA by reducing sugar, and inflicting oxidative and hydrolytic damage. Therefore, the DNA recovery yield is usually lower for formalin-fixed specimens than ethanol-fixed or frozen specimen. In this study, genomic DNA was extracted from the modified protocol of Azuma et al. [16] and Li et al. [17]. We extended the time of incubation up to $24 \mathrm{hr}$, and SDS and proteinase K were added during the incubation process. Most of the formalin-preserved samples yielded weak or no PCR amplification, but secondary PCR using the PCR products obtained from the first round of PCR amplifications as a template make it possible to use the PCR product for direct sequencing. The longest time period of formalin preservation used for molecular identification was the specimen (labeled as $T$. saginata by the original collector) that had been isolated, and kept in 10\% formalin since 1935 in the Department of Parasitology, Seoul National University. Very interestingly, cox1 sequence analysis of the specimen identified it as T. asiatica. Overall results were 3 T. solium, 51 T. asiatica, and 14 T. saginata. These results clearly indicate that all 3 human Taneia tapeworms are sympatrically distributed in Korea, with T. asaitica infections accounting for three-quarters of the total Taenia infections.

\section{ACKNOWLEDGEMENTS}

This work was supported by a research grant from Chungbuk National University in 2008. Parasite materials used in this study were provided by the Parasite Resource Bank of Korea, National Research Center (R21-2005-000-10007-0), the Republic of Korea. 


\section{REFERENCES}

1. Min DY. Cestode infections in Korea. Korean J Parasitol 1990; 28(suppl): 123-144.

2. Inoba J. Human taeniasis caused by eating meat in Chosen. Chuo Juikai Zasshi 1924; 37: 229-239.

3. Seo BS, Rim HJ, Loh IK. Study on the status of helminthic infections in Koreans. Korean J Parasitol 1969; 7: 53-70.

4. Eom KS, Rim HJ. Epidemiological understanding of Taenia tapeworm infections with special reference to Taenia asiatica in Korea. Korean J Parasitol 2001 39: 267-283.

5. Eom KS, Rim HJ. Morphologic descriptions of Taenia asiatica sp. n. Korean J Parasitol 1993; 31: 1-6.

6. Eom KS, Jeon HK, Kong Y, Hwang UW, Yang Y, Li X, Xu L, Feng Z, Pawlowski ZS, Rim HJ. Identification of Taenia asiatica in China: molecular, morphological and epidemiological analysis of a Luzhai isolate. J Parasitol 2002; 88: 758-764.

7. Ito $A$, Nakao M, Wandra T. Human taeniasis and cysticercosis in Asia. Lancet 2003; 362: 1918-1920.

8. Anantaphruti MT, Yamasaki H, Nakao M, Waikagul J, Watthanakulpanich D, Nuamtangong S, Maipanich S, Pubampen S, Sanguankiat S, Muennoo C, Nakaya K, Sato MO, Sako Y, Okamoto M, Ito A. Sympatric occurrence of Taenia solium, T. saginata, and T. asiatica, Thailand. Emerg Infec Dis 2007; 13: 1413-1416.

9. Fan PC, Lin CY, Chen CC, Chung WC. Morphological description of Taenia saginata asiatica (Cyclophyllidea: Taeniidae) from man in Asia. J Helminthol 1995; 69: 299-303.

10. Simanjuntak GM, Margono SS, Okamoto M, Ito A. Taeniasis/ cysticercosis in Indonesia as an emerging disease. Parasitol Today 1997; 13: 321-323.

11. Willingham AL 3rd, De NV, Doanh NQ, Cong Le D, Dung TV, Dorny P, Cam PD, Dalsgaard A. Current status of cysticercosis in
Vietnam. Southeast Asian J Trop Med and Public Health 2003; 34(suppl 1): 35-50.

12. Bowles J, McManus DP. Genetic characterization of the Asian Taenia, a newly described taeniid cestodes of human. Am J Trop Med and Hyg 1994; 50: 33-44.

13. Yamasaki H, Nakao M, Sako Y, Nakaya K, Sato MO, Mamuti W, Okamoto M, Ito A. DNA differential diagnosis of human taeniid cestodes by base excision sequence scanning thymine-base reader analysis with mitochondrial genes. J Clini Microbiol 2002; 40: 3818-3821.

14. Gonzales LM, Montero E, Morakote N, Pueute S, Diaz De Tuesta JL, Serra T, Lopez-Velez R, McManus DP, Harrison LJS, Parkhouse RME, Garate T. Differential diagnosis of Taenia saginata and Taenia saginata asiatica taeniasis through PCR. Diagno Microbiol and Infect Disease 2004; 49: 183-188.

15. Yamasaki H, Allan JC, Sato MO, Nakao M, Sako Y, Nakaya K, Qiu D, Mamuti W, Craig PS, Ito A. DNA differential diagnosis of taeniasis and cysticercosis by multiplex PCR. J Clini Microbiol 2004; 42: 548-553.

16. Azuma H, Okamoto M, Oku Y, Kamiya M. Intraspecific variation of Taenia taeniaeformis as identified by various criteria. Parasitol Res 1995; 81: 103-108.

17. Li J, Liao X, Yang H. Molecular characterization of a parasitic tapeworm (Ligula) based on DNA sequences from formalin-fixed specimens. Biochem Genet 2000; 38: 309-322.

18. Thompson JD, Gibson TJ, Plewniak F, Jeanmougin F, Higgins DG. The CLUSTAL X windows interface: flexible strategies for multiple sequence alignment aided by quality analysis tools. Nucleic Acids Res 1997; 25: 4876-4882.

19. Kumar S, Tamura K, Nei M. MEGA3: Integrated software for molecular evolutionary genetics analysis and sequence aligment. Brief Bioinformatics 2004; 5: 150-163. 
